\title{
Avaliação de indicadores em estudos com ruminantes: digestibilidade
}

\author{
Marcelo de Andrade Ferreira ${ }^{1}$, Sebastião de Campos Valadares Filho ${ }^{2}$, Marcos Inácio \\ Marcondes ${ }^{3}$, Mônica Lopes Paixão ${ }^{4}$, Mário Fonseca Paulino ${ }^{2}$, Rilene Ferreira Diniz Valadares ${ }^{5}$ \\ ${ }^{1}$ Departamento de Zootecnia /UFRPE - Pesquisador do CNPq. \\ ${ }^{2}$ DZO/UFV - Pesquisador do CNPq. \\ ${ }^{3}$ Mestrado/DZO/UFV. \\ ${ }^{4}$ Doutorado/DZO/UFV. \\ ${ }^{5}$ DVT/UFV-Bolsita do CNPq.
}

RESUMO - Foram conduzidos dois experimentos com o objetivo de avaliar os indicadores internos fibra em detergente neutro indigestível (FDNi) e fibra em detergente ácido (FDAi), obtidos por incubação in situ durante seis dias, e os indicadores externos óxido crômico $\left(\mathrm{Cr}_{2} \mathrm{O}_{3}\right)$, dióxido de titânio $\left(\mathrm{TiO}_{2}\right)$ e lignina isolada, purificada e enriquecida $\left(\right.$ LIPE $\left.{ }^{\circledR}\right)$ em dois esquemas de coleta total de fezes ( 3 ou 5 dias) para estimativa da digestibilidade em bovinos. O delineamento experimental foi o de blocos ao acaso com parcelas subdivididas. No primeiro experimento, foram utilizadas cinco novilhas mestiças alimentadas com cana-de-açúcar com $1 \%$ de ureia/sulfato de amônio e concentrado (1\% do peso vivo). Não houve diferenças entre as metodologias de coleta para a digestibilidade da matéria seca. Quando estimada utilizando-se FDAi, a digestibilidade dos nutrientes foi subestimada, mas, quando estimada utilizando-se FDNi e os indicadores externos (óxido crômico, dióxido de titânio e LIPE ${ }^{\circledR}$ ), não diferiu significativamente daquela determinada por coleta total de fezes. No segundo experimento, foram utilizadas oito vacas em lactação alimentadas com silagem de milho e $4 \mathrm{~kg}$ de concentrado. Não houve diferença na digestibilidade da matéria seca entre os períodos de coleta. A digestibilidade dos nutrientes, quando estimada utilizando-se FDNi, foi superestimada, mas, quando estimada utilizando-se FDAi e os indicadores externos (óxido crômico, dióxido de titânio e LIPE $\left.{ }^{\circledR}\right)$, não diferiu significativamente daquela determinada por coleta total de fezes. Três dias de coleta são suficientes para estimativa da digestibilidade e os indicadores testados são eficientes na determinação da digestibilidade.

Palavras-chave: coleta total, indicadores externos, indicadores internos

\section{Evaluation of markers in ruminant trials: digestibility}

\begin{abstract}
Two studies were carried out to evaluate indigestible neutral detergent fiber (iNDF) and indigestible acid detergent fiber (iADF) as internal markers obtained by 144-h incubation in situ and chromium oxide $\left(\mathrm{Cr}_{2} \mathrm{O}_{3}\right)$, titanium dioxide $\left(\mathrm{TiO}_{2}\right)$ and isolated, purified and enriched lignin $\left(\mathrm{LIPE}^{\circledR}\right)$ as external markers, and two total fecal collection schemes ( 3 or 5 days) to estimate digestibility in bovines. The experimental procedure was a randomized block design in a split plot arrangement. In the first trial, five crossbreed heifers fed sugar cane plus $1 \%$ of urea/ammonium sulfate and concentrate ( $1 \%$ of body weight) were used. There was no difference for dry matter digestibility when the collection schemes were compared ( 5 days vs 3 days). The nutrient digestibility estimated by iADF was underestimated and those estimated by iNDF, chromium oxide, titanium dioxide and LIPE ${ }^{\circledR}$, did not differ from the digestibility calculated on total fecal collection. In the second trial, eight lactating cows fed corn silage and concentrate (4 kg/cow/day) were used. There was no difference for dry matter digestibility when the collection schemes were compared (5 days vs 3 days). The nutrient digestibility estimated by iNDF was overestimated and those estimated by iADF, chromium oxide, titanium dioxide and LIPE ${ }^{\circledR}$, did not differ from the digestibility calculated on total fecal collection. Three days of fecal collection and the markers tested can safely be used to estimate digestibility.
\end{abstract}

Key Words: external markers, internal markers, total collection

\section{Introdução}

A avaliação do valor nutritivo dos alimentos consumidos por ruminantes em condições de pastejo ou confinados tem sido um desafio para os nutricionistas. A digestibilidade é um dos parâmetros importantes para essa avaliação; entretanto, a determinação pela coleta total de fezes requer rigoroso controle da ingestão e excreção, o que torna esse método tradicional trabalhoso e oneroso (Berchielli et al., 2000). 
Diante desse inconveniente, foi desenvolvida a técnica de determinação da digestibilidade pelos indicadores (externos ou internos), que não requer o manuseio de grande quantidade de material e permite obter informações como a quantidade total de alimentos ou de nutrientes específicos, a taxa de passagem da digesta por todo o trato digestivo e a digestibilidade de todo alimento ou de nutrientes específicos.

Vários indicadores internos têm sido testados para estimar a digestibilidade: cinza insolúvel em ácido, cinza insolúvel em detergente ácido, lignina em detergente ácido indigestível, FDNi e FDAi. A variabilidade nos resultados das estimativas de digestibilidade obtidas com o uso de indicadores internos pode ser decorrente da metodologia de análise (Detmann et al., 2001). Lippke et al.(1986) apontaram para falta de padronização no método de determinação.

O óxido crômico é o indicador externo mais comumente usado na estimativa da digestibilidade, principalmente por seu baixo custo e pela facilidade de análise. Entretanto, recuperação diferente de $100 \%$, variação entre animais na recuperação fecal e variação na concentração nas fezes no decorrer do dia são alguns dos problemas relacionados a esse indicador (Titgemeyer, 1997).

Titgemeyer et al. (2001) demonstraram que o dióxido de titânio pode ser utilizado como indicador externo, em alternativa ao óxido crômico, em estudos de digestão e pode ser adicionado legalmente ao alimento em quantidades que não excedam 1,0\% do produto final (AAFCO, 1996). Uma alternativa é um indicador baseado na molécula de lignina, denominado LIPE $^{\circledR}$, um indicador externo de digestibilidade desenvolvido especificamente para pesquisas (Rodriguez et al., 2006).

Em pesquisas com ruminantes, geralmente são empregados cinco dias para coleta de fezes. A diminuição desse período de coleta, além de diminuir o estresse dos animais, poderia resultar em menores quantidades de amostras a serem manuseadas e analisadas e tornaria os ensaios dessa natureza menos onerosos e trabalhosos.

Objetivou-se com este estudo avaliar dois indicadores internos (FDA e FDN indigestíveis), obtidos por meio da incubação in situ durante seis dias, três indicadores externos (óxido crômico, dióxido de titânio e lignina purificada e enriquecida, $\operatorname{LIPE}^{\circledR}$ ), além de dois períodos de coleta total de fezes (3 ou 5 dias) para estimativa da digestibilidade dos nutrientes em bovinos.

\section{Material e Métodos}

Foram realizados dois experimentos. O primeiro foi conduzido no Laboratório de Nutrição Animal do Departa- mento de Zootecnia da UFV, utilizando-se cinco novilhas mestiças fistuladas no rúmen, com peso vivo (PV) inicial de $191 \pm 22,9 \mathrm{~kg}$, alimentadas com cana-de-açúcar tratada com $1 \%$ de ureia + sulfato de amônio (SA) e concentrado na proporção de $1 \%$ do peso vivo, com base na matéria natural. Os animais foram mantidos em regime de confinamento, alojados em baias individuais cobertas, com piso de concreto revestido de borracha, com comedouro de alvenaria e bebedouros automáticos individuais.

A dieta foi fornecida à vontade, em duas porções diárias, permitindo-se sobras de 5 a $10 \%$ do total fornecido, composta (base na matéria seca) de cana de açúcar (61,2\%), ureia/SA (2,0\%) e concentrado (35,8\%) (Tabela 1$)$. O concentrado (1\% do peso vivo, PV) foi fornecido separadamente da cana. O óxido crômico e o dióxido de titânio (10 g/novilha/dia) foram fornecidos juntamente com o concentrado. O LIPE ${ }^{\circledR}$ (1 cápsula/novilha/dia) foi colocado diretamente no rúmen dos animais.

O segundo experimento foi realizado na Unidade de Ensino, Pesquisa e Extensão em Gado de Leite (UEPE-GL) do Departamento de Zootecnia da UFV.

Foram utilizadas oito em vacas em lactação com $588,3 \pm$ 43,3 kg de PV e produção diária de 12,35 +1,44 kg de leite. Os animais foram mantidos em confinamento, alojados em baias individuais cobertas, com piso de concreto revestido de borracha, com comedouro de alvenaria e bebedouros automáticos individuais.

A dieta era composta (base na MS) de silagem de milho (74\%) e concentrado (26\%) (Tabela 2) composto de fubá de milho (61,1\%), farelo de soja (33,7\%), bicarbonato de sódio (1\%), fosfato bicálcico $(1,72 \%)$, sal comum $(1,24 \%)$ e complexo vitamínico-mineral (1,24\%). A silagem foi fornecida à vontade em quatro porções diárias para evitar o mínimo possível de sobras. Quando presentes, as sobras eram moídas e novamente ofertadas aos animais. O concentrado

Tabela 1 - Composição nutricional dos ingredientes da dieta oferecida às novilhas (\% na MS)

\begin{tabular}{lcccc}
\hline Item & $\begin{array}{c}\text { Cana-de- } \\
\text { açúcar }\end{array}$ & $\begin{array}{c}\text { Farelo } \\
\text { de soja }\end{array}$ & $\begin{array}{c}\text { Fubá } \\
\text { de milho }\end{array}$ & Dieta \\
\hline Matéria seca (\%) & 30,32 & 88,65 & 85,14 & 53,22 \\
Matéria orgânica & 97,22 & 94,03 & 98,94 & 96,57 \\
Proteína bruta & 1,95 & 49,14 & 8,17 & 11,28 \\
Extrato etéreo & 3,23 & 1,25 & 2,56 & 2,30 \\
Carboidratos totais & 92,04 & 43,64 & 88,21 & 84,37 \\
FDNcp & 39,57 & 15,84 & 16,33 & 31,24 \\
CNFcp & 52,48 & 27,80 & 71,88 & 52,22 \\
FDNi & 22,5 & 2,41 & 1,70 & - \\
FDAi & 17,07 & 0,86 & 0,72 & - \\
\hline
\end{tabular}

FDNcp = fibra em detergente neutro corrigida para cinzas e proteína; $\mathrm{CNF} c \mathrm{c}=$ carboidratos não-fibrosos corrigidos para cinzas e proteína; $\mathrm{FDNi}=$ fibra em detergente neutro indigestível; FDAi = fibra em detergente ácido indigestível. 
Tabela 2 - Composição nutricional dos ingredientes da dieta oferecida às vacas (\% na MS)

\begin{tabular}{lccc}
\hline Item & Silagem de milho & Concentrado & Dieta \\
\hline Matéria seca & 35,67 & 87,39 & 41,44 \\
Matéria orgânica & 94,7 & 91,98 & 93,99 \\
Proteína bruta & 7,17 & 24,15 & 11,60 \\
Extrato etéreo & 3,03 & 2,43 & 2,99 \\
Carboidratos totais & 84,50 & 65,4 & 80,97 \\
Fibra em detergente neutro & 58,20 & 17,76 & 44,30 \\
Carboidratos não-fibrosos & 26,30 & 47,64 & 36,68 \\
FDNi & 25,49 & 1,87 & - \\
FDAi & 12,65 & 0,38 & - \\
\hline
\end{tabular}

FDNi = fibra em detergente neutro indigestível; FDAi = fibra em detergente ácido indigestível.

(4 kg/vaca.dia) foi fornecido em recipiente separado da silagem em duas porções diárias. O óxido crômico, o dióxido de titânio (10g/vaca/dia) e o LIPE® (1 cápsula/vaca/dia) foram fornecidos juntamente com o concentrado.

$\mathrm{O}$ ensaio de digestibilidade, nos dois experimentos, teve duração de 15 dias: 10 de adaptação e 5 para coleta total de fezes e amostras de alimento, sobras e fezes. O fornecimento dos indicadores externos iniciou-se sete dias antes do início do período de coleta.

As fezes foram coletadas diretamente no piso das baias e, para que não houvesse contaminação com urina, foram colocadas sondas de Folley n ${ }^{0} 26$ nas novilhas e vacas.

Durante o período de coleta, foram colhidas amostras diárias dos alimentos, das sobras e das fezes, a fim de se obter uma amostra composta por animal e por período de coleta (três ou cinco dias). Essas amostras foram devidamente armazenadas a $-15^{\circ} \mathrm{C}$ e, depois de secas, foram processadas em moinho com peneira dotada de crivos de $1 \mathrm{~mm}$ e submetidas a análises laboratoriais.

As análises para determinação dos teores de matéria seca (MS), matéria mineral (MM), nitrogênio total (N), extrato etéreo (EE) e cromo seguiram as recomendações de Silva \& Queiroz (2002). Para determinação da FDN, 0,5 g de amostra foi acondicionada em sacos de TNT (tecidonão-tecido) previamente secos e pesados, e submetidos à fervura com solução de detergente neutro por 1 hora (Van Soest \& Robertson, 1985), lavados com água quente e acetona, secos e pesados. O resíduo foi considerado FDN.

O teor de dióxido de titânio foi determinado segundo Myers et al.(2004). Uma amostra de 0,5 g de fezes foi digerida, por 2 horas, em temperatura de $400^{\circ} \mathrm{C}$, em tubos para determinação de proteína. Após a digestão, $10 \mathrm{~mL}$ de $\mathrm{H}_{2} \mathrm{O}_{2}$ (30\%) foram adicionados lentamente e o material do tubo, transferido para um béquer e completado com água destilada até 100 g. Logo após esse procedimento o material do béquer foi transferido para balões de $100 \mathrm{~mL}$ e adicionados de mais 3 gotas de $\mathrm{H}_{2} \mathrm{O}_{2}$ (30\%). Na digestão foram utilizados
15 mL de ácido sulfúrico e $5 \mathrm{~g}$ da mistura digestora para proteína (macro KJELDAHL). Uma curva padrão foi preparada com 0, 2, 4, 6, 8 e 10 mg de dióxido de titânio e as leituras realizadas em espectrofotômetro com comprimento de onda de $410 \mathrm{~nm}$

O LIPE foi analisado no laboratório de nutrição animal da EV/UFMG, em espectrofotômetro com detector de luz no espectro do infravermelho (FTIV), modelo Varian 099-2243. Amostras de fezes secas e moídas a $2 \mathrm{~mm}$ foram pastilhadas com $\mathrm{KBr}$ e a concentração do LIPE determinada.

Os carboidratos totais (CT) foram estimados segundo Sniffen et al. (1992):

$$
\mathrm{CT}=100-(\mathrm{PB} \%+\mathrm{EE} \%+\text { Cinzas\% }) .
$$

Para a dieta com ureia,os teores de carboidratos nãofibrosos (CNF) foram estimados segundo Hall (2000): $\mathrm{CNF}=100-[(\mathrm{PB} \%-\mathrm{PB} \%$ derivada da ureia + ureia\% $)+\mathrm{EE} \%$ + FDN\% + cinzas\%]. E, para a dieta sem ureia, foi usada a equação preconizada por Mertens (1997): CNF = $100-$ (FDN\% + PB\% + EE\% + CINZAS\%).

Os teores de nutrientes digestíveis totais (NDT) foram calculados segundo Weiss (1999):

$\mathrm{NDT}(\%)=\mathrm{PBD} \%+\mathrm{FDND} \%+\mathrm{CNFD} \%+(\mathrm{EED} \% * 2,25)$.

Para determinação da FDN e FDA indigestíveis, 0,5 g de amostra do volumoso, das fezes e das sobras e $1,0 \mathrm{~g}$ de amostra de alimento concentrado foram acondicionadas em sacos de TNT, previamente secos e pesados, e incubadas por 144 horas no rúmen de uma vaca. Após esse período, os sacos foram retirados, lavados em água corrente até seu total clareamento. Após esse procedimento, os sacos foram secos e fervidos por 1 hora em solução de detergente neutro (Van Soest \& Robertson, 1985), lavados com água quente e acetona, secos e pesados e seu resíduo, considerado FDNi. Para a FDAi, adotou-se o mesmo procedimento com solução de detergente ácido.

A produção de matéria seca fecal foi determinada pela seguinte fórmula: PMSF = consumo do indicador $(\mathrm{kg}) /$ concentração do indicador nas fezes (\%).

O delineamento experimental foi o de blocos casualisados em parcelas subdivididas, de modo que, nas parcelas, constaram os tratamentos (indicadores), nas subparcelas os períodos de coleta (3 ou 5 dias), e os animais foram considerados blocos. Os dados foram avaliados por meio de análise de variância e as médias, quando necessário, comparadas pelo teste de Tukey, utilizando-se o Sistema de Análises Estatísticas e Genéticas - SAEG (UFV, 1997).

\section{Resultados e Discussão}

Não houve interação entre indicador e dias de coleta $(\mathrm{P}>0,05)$ para os coeficientes de digestibilidade da matéria 
seca (Tabelas 3 e 4). Assim, os efeitos do indicador e dias de coleta foram analisados separadamente.

Não houve diferença $(\mathrm{P}>0,05)$, independentemente do indicador utilizado, na digestibilidade da matéria seca determinada com três ou cinco dias de coleta, assim, o procedimento mais simples pode ser adotado e resulta em menores quantidades de amostras para manuseio e análise, diminuindo o trabalho em ensaios desta natureza.

Como não houve diferença entre os períodos de coleta, os dados de digestibilidade dos diferentes nutrientes analisados foram referentes ao período de três dias (Tabela 4).

Quando o volumoso utilizado foi a cana-de-açúcar, o pior resultado foi verificado com a FDAi, ao passo que a FDNi foi o indicador interno menos preciso quando utilizada silagem de milho como volumoso.

Berchielli et al.(2005) verificaram que o comportamento dos indicadores internos FDNi e FDAi, incubados in situ ou in vitro diferiu de acordo com o volumoso utilizado. Esses autores verificaram que a FDAi resultante da incubação in vitro por 144 horas não diferiu da coleta total de fezes na estimativa da produção de matéria seca fecal de bovinos alimentados com silagem de milho. Quando utilizada cana como volumoso, nenhum dos indicadores estimou corretamente a produção de matéria seca fecal. Quando fornecido feno de capim-tifton como volumoso, a FDNi incubada in vitro e a FDAi incubada in situ permitiram estimar a produção de matéria seca fecal de forma semelhante à coleta total.

Tabela 3 - Coeficientes de digestibilidade aparente da matéria seca (\%) determinada com diversos indicadores em novilhas e vacas em lactação

\begin{tabular}{|c|c|c|}
\hline & \multicolumn{2}{|c|}{ Dia de coleta } \\
\hline & 3 & 5 \\
\hline Indicador & \multicolumn{2}{|c|}{ Novilhas } \\
\hline Coleta total & $75,77 \mathrm{Aa}$ & $76,41 \mathrm{Aa}$ \\
\hline $\operatorname{LIPE}^{\circledR}$ & $76,29 \mathrm{Aa}$ & $76,48 \mathrm{Aa}$ \\
\hline $\mathrm{Cr}_{2} \mathrm{O}_{3}$ & $73,55 \mathrm{Aa}$ & $73,58 \mathrm{Aa}$ \\
\hline $\mathrm{TiO}_{2}{ }^{3}$ & $75,91 \mathrm{Aa}$ & $76,60 \mathrm{Aa}$ \\
\hline FDAi & $69,12 \mathrm{Ba}$ & $69,49 B \mathrm{a}$ \\
\hline FDNi & $75,81 \mathrm{Aa}$ & $75,86 \mathrm{Aa}$ \\
\hline CV (\%) & \multicolumn{2}{|c|}{1,87} \\
\hline
\end{tabular}

Vacas em lactação

$\begin{array}{lll}\text { Coleta total } & 62,75 \mathrm{Aa} & 62,84 \mathrm{Aa} \\ \mathrm{LIPE} \AA & 61,33 \mathrm{Aa} & 61,06 \mathrm{Aa} \\ \mathrm{Cr}_{2} \mathrm{O}_{3} & 62,10 \mathrm{Aa} & 63,46 \mathrm{Aa} \\ \mathrm{TiO}_{2} & 64,46 \mathrm{Aa} & 62,60 \mathrm{Aa} \\ \mathrm{FDAi} & 62,26 \mathrm{Aa} & 61,99 \mathrm{Aa} \\ \text { FDNi } & 66,80 \mathrm{Ba} & 67,39 \mathrm{Ba}\end{array}$

CV (\%)

4,67

Médias seguidas de letras iguais, maiúsculas nas colunas e minúsculas nas linhas, não diferem $(\mathrm{P}>0,05)$ entre si.
Berchielli et al. (2000) em estudo para comparação de indicadores, utilizaram como volumoso silagem de milho e verificaram que a FDNi e a FDAi_incubadas in vitro por 144 horas permitiram estimar a digestibilidade da MS, PB, EE, FDN, energia bruta e o teor de NDT de maneira similar à coleta total de fezes.

İtavo et al. (2002) e Zeoula et al (2000) concluíram que a digestibilidade da matéria seca foi subestimada quando utilizada a FDN e FDA indigestíveis in situ. Segundo Berchielli et al.(2005), a subestimativa da digestibilidade da matéria seca sugere que poderia ter ocorrido perda de indicador no processo digestivo ou ainda, durante a rotina das análises laboratoriais. De acordo com esses autores, as prováveis razões para variações na eficácia da fração fibrosa indigestível seriam a constituição da fibra de cada volumoso, que desempenha importante papel e pode afetar a taxa e a extensão da degradação dessa fibra; a seletividade da dieta pelos animais, uma vez que o resíduo que sobra no cocho é, normalmente, rico em material indigestível, o que torna importante a realização da correção nos dados de consumo do indicador em relação à fibra indigestível presente nas sobras e a perda de partículas de alimento e fezes pelos poros dos sacos durante a incubação ruminal.

Ressalta-se que, no experimento com novilhas, amostras de sobras também foram incubadas, eliminando esse efeito, e, no experimento com vacas em lactação, as sobras, geralmente palha, foram moídas e novamente ofertadas aos animais.

Detman et al.(2001) avaliaram o óxido crômico e diversos indicadores internos na determinação do consumo de novilhos mestiços e observaram que a MS e a FDN indigestíveis apresentaram diferença entre si nos resultados de consumo e a FDAi mostrou resultados variáveis. Os autores salientaram que esse resultado poderia ser em decorrência da técnica de análise da FDA, obtida pelo método sequencial, que possibilitaria o acúmulo de erros. Contudo, no experimento com vacas, o teor de FDAi dos alimentos e das fezes foi obtido pela análise direta do resíduo resultante da incubação por 144 horas.

Apesar das desvantagens citadas por Titgemeyer (1997), os resultados obtidos com o óxido crômico não diferiram daqueles observados com a coleta total de fezes, o que comprova ser um bom indicador, de baixo custo, fácil administração e facilidade de análise. Nos dois experimentos, o óxido crômico foi administrado em duas doses diárias, juntamente com o concentrado, o que pode ter reduzido a variação diurna na sua excreção.

Da mesma forma, o dióxido de titânio também permitiu estimativas de digestibilidade semelhantes à coleta total de fezes, corroborando as afirmações de Titegmeyer et al.(2001) 
Tabela 4 - Coeficientes de digestibilidade (\%) e teor de nutrientes digestíveis totais determinados com diversos indicadores em novilhas e vacas em lactação

\begin{tabular}{|c|c|c|c|c|c|c|c|}
\hline \multirow[b]{3}{*}{ Coeficientes de digestibilidade } & \multicolumn{7}{|c|}{ Indicador } \\
\hline & Coleta total ${ }^{1}$ & $\operatorname{LIPE}^{\circledR}$ & $\mathrm{Cr}_{2} \mathrm{O}_{3}$ & $\mathrm{TiO}_{2}$ & FDAi & FDNi & CV (\%) \\
\hline & \multicolumn{7}{|c|}{ Novilhas } \\
\hline Matéria orgânica & $77,23 a$ & $77,76 a$ & $75,15 a$ & $77,38 \mathrm{a}$ & $71,02 b$ & $77,31 \mathrm{a}$ & 2,31 \\
\hline Proteína bruta & $73,36 \mathrm{a}$ & $73,76 a$ & $71,01 \mathrm{a}$ & $73,52 \mathrm{a}$ & $65,89 b$ & $73,22 \mathrm{a}$ & 2,90 \\
\hline Carboidratos totais & $78,82 \mathrm{a}$ & $79,35 a$ & $76,86 a$ & $78,95 \mathrm{a}$ & $73,06 \mathrm{~b}$ & $78,92 \mathrm{a}$ & 2,11 \\
\hline Extrato etéreo & $83,97 a$ & $83,86 a$ & $82,62 \mathrm{a}$ & $83,98 a$ & $79,27 b$ & $83,61 \mathrm{a}$ & 1,58 \\
\hline Carboidratos não-fibrosos & $93,61 \mathrm{a}$ & 93,67 a & $93,11 \mathrm{a}$ & $93,70 a$ & $91,82 b$ & $93,58 a$ & 0,58 \\
\hline Fibra em detergente neutro & $45,52 \mathrm{a}$ & $46,96 a$ & $40,33 a$ & $45,73 a$ & $30,75 b$ & $45,81 \mathrm{a}$ & 9,98 \\
\hline Teor de nutrientes digestíveis totais & $81,62 \mathrm{a}$ & $82,13 a$ & $79,54 a$ & $81,75 a$ & $75,44 b$ & $81,68 \mathrm{a}$ & 2,16 \\
\hline \multicolumn{3}{|l|}{ Coeficientes de digestibilidade } & \multicolumn{5}{|c|}{ Vacas em lactação } \\
\hline Matéria orgânica & $66,08 \mathrm{a}$ & $64,85 a$ & $65,47 a$ & $67,63 a b$ & $65,62 \mathrm{a}$ & $69,77 b$ & 3,37 \\
\hline Proteína bruta & $61,75 a$ & $60,35 a$ & $60,98 a$ & $63,48 \mathrm{ab}$ & $61,23 a$ & $65,45 b$ & 4,13 \\
\hline Carboidratos totais & $65,73 a$ & $64,52 \mathrm{a}$ & $65,12 \mathrm{a}$ & $67,29 a b$ & $65,25 a$ & $69,44 b$ & 3,35 \\
\hline Extrato etéreo & $78,44 a$ & $77,73 a$ & $77,97 a$ & $79,55 a b$ & $78,45 a$ & $80,98 b$ & 1,94 \\
\hline Carboidratos não-fibrosos & $84,22 \mathrm{a}$ & $83,58 a$ & $84,01 \mathrm{a}$ & $84,93 a b$ & $83,98 a$ & $85,93 b$ & 1,31 \\
\hline Fibra em detergente neutro & $50,42 \mathrm{a}$ & $48,73 a$ & $49,48 a$ & $52,69 \mathrm{ab}$ & $49,74 a$ & $55,78 b$ & 6,27 \\
\hline Teor de nutrientes digestíveis totais & $65,77 a$ & $64,52 \mathrm{a}$ & $65,18 a$ & $67,32 \mathrm{ab}$ & $65,31 \mathrm{a}$ & $71,00 \mathrm{~b}$ & 3,29 \\
\hline
\end{tabular}

Médias seguidas de letras iguais na linha não diferem entre si $(\mathrm{P}>0,05)$.

de que o dióxido de titânio pode ser usado em estudos de digestão em ruminantes.

O LIPE ${ }^{\circledR}$ também estimou de forma satisfatória a digestibilidade dos nutrientes, que não diferiu da digestibilidade determinada pela coleta total de fezes.

Saliba et al.(2003) verificaram que não houve diferença para digestibilidade da MS do feno de capim-tifton quando compararam os dados obtidos por meio de coleta total e LIPE $^{\circledR}$ (63,23 vs 64,78\%, respectivamente). Cameron (2005) inserir nas referências citado por Rodrigues et al.(2006), em experimento com vacas em lactação alimentadas com dietas à base de feno de alfafa, não verificaram diferença na produção de matéria seca fecal quando comparaam os dados obtidos por meio de coleta total e $\operatorname{LIPE}^{\circledR}(4,61 \mathrm{vs}$ $4,47 \mathrm{~kg} /$ dia, respectivamente).

De acordo com os resultados verificados nos dois experimentos, o óxido crômico ou de dióxido de titânio, adicionados ao concentrado e fornecido duas vezes ao dia, e o LIPE ${ }^{\circledR}$ podem ser utilizados para estimativa da digestibilidade em ruminantes. A escolha do indicador externo vai depender da facilidade de análise, disponibilidade e o preço.

Com relação aos indicadores internos os resultados dos dois experimentos permitem inferir que ambos, FDNi e FDAi, podem ser utilizados em estudos de digestibilidade. Todavia, em virtude da grande variabilidade de resultados encontrados na literatura, são necessários cuidados na preparação de amostras e nas técnicas de análise.

A alternativa de se empregar três dias de coleta de fezes parece ser bastante interessante, pois poderia reduzir o estresse dos animais. Além disso, menores quantidades de amostras são manuseadas e analisadas, o que tornaria os ensaios desta natureza, menos onerosos e trabalhosos.

\section{Conclusões}

Recomendam-se três dias de coleta de amostras de fezes para estimativa da digestibilidade. A fibra em detergente neutro indigestível permite estimar a digestibilidade de maneira semelhante à coleta total de fezes quando utilizada cana-de-açúcar como volumoso. O mesmo ocorre com a fibra em detergente ácido indigestível quando utilizada silagem de milho como volumoso. Os indicadores externos óxido crômico, dióxido de titânio e LIPE ${ }^{\circledR}$ permitem estimar a digestibilidade de maneira semelhante ao método de coleta total de fezes.

\section{Literatura Citada}

ASSOCIATION OF AMERICAN FEED CONTROL OFFICIALS AAFCO. Official publication. Atlanta: 1996. 162p.

BERCHIELLI, T.T.; ANDRADE, P.; FURLAN, C.L. Avaliação de indicadores internos em ensaios de digestibilidade. Revista Brasileira de Zootecnia, v.29, n.3, p.830-833, 2000.

BERCHIELLI, T.T.; OLIVEIRA, S.G.; CARRILHO, E.N.V.M. et al. Comparação de marcadores para estimativas de produção fecal e de fluxo de digesta em bovinos. Revista Brasileira de Zootecnia, v.34, n.3, p.987-996, 2005.

DETMANN, E.; VALADARES FILHO, S.C.; PAULINO, M.F. et al. Cromo e indicadores internos na determinação do consumo de novilhos mestiços, suplementados, a pasto. Revista Brasileira de Zootecnia, v.30, n.5, p.1600-1609, 2001.

HALL, M.B. Calculation of non-structural carbohydrate content of feeds that contain non-protein nitrogen. Gainesville: University of Florida, 2000. p.A-25 (Bulletin, 339). 
ÍTAVO, L.C.V.; VALADARES FILHO, S.C.; FERREIRA DA SILVA, F. et al. Comparação de indicadores e metodologia de coleta para estimativas de produção fecal e fluxo de digesta em bovinos. Revista Brasileira de Zootecnia, v.31, n.4, p.1833-1839, 2002.

LIPPKE, H.; ELLIS, W.C.; JACOBS, B.F. Recovery of indigestible fiber from feces of sheep and cattle on forage diets. Journal of Dairy Science, v.69, n.2, p.403-412, 1986.

MERTENS, D.R. Creating a system for meeting the fiber requeriments of dairy cows. Journal of Dairy Science, v.80, n.7, p.1463-1481, 1997.

MYERS, W.D.; LUDDEN, P.A.; NAYIGIHUGU, V. et al. Technical Note: a procedure for the preparation and quantitative analysis of samples for titanium dioxide. Journal of Animal Science, v.82, n.1, p.179-183, 2004.

RODRIGUEZ, N.M.; SALIBA, E.O.S.; GUIMARÃES JR., R. Uso de indicadores para estimativa de consumo a pasto e digestibilidade. In: REUNIÃO ANUAL DA SOCIEDADE BRASILEIRA DE ZOOTECNIA, 43., 2006, João Pessoa. Anais... João Pessoa: Sociedade Brasileira de Zootecnia, 2006. p.323-352.

SALIBA, E.O.S.; RODRIGUEZ, N.M.; PILÓ-VELOSO, D. et al. Estudo comparativo da digestibilidade pela técnica da coleta total com lignina purificada como indicador de digestibilidade para ovinos em experimento com feno de tifton 85. In: REUNIÃO ANUAL DA SOCIEDADE BRASILEIRA DE ZOOTECNIA, 40., 2003, Santa Maria. Anais... Santa Maria: Sociedade Brasileira de Zootecnia, 2003. (CD-ROM).
SILVA, D.J.; QUEIROZ, A.C. Análise de alimentos: métodos químicos e biológicos. 3.ed. Viçosa, MG: Universidade Federal de Viçosa, 2002. 235p.

SNIFFEN, C.J.; O`CONNOR, J.D.; Van SOEST, P.J. et al. A net carbohydrate and protein system for evaluation cattle diets. 2 . Carbohydrates and protein availability. Journal of Animal Science, v.70, n.11, p.3562-3577, 1992.

TITGEMEYER, E.C. Design and interpretation of nutrient digestion studies. Journal of Animal Science, v.75, n.8, p.2235-2247, 1997.

TITGEMEYER, E.C.; ARMENDARIZ, C.K.; BINDEL, D.J. et al. Evaluation of titanium dioxide as a digestibility marker for cattle. Journal of Animal Science, v.79, n.4, p.1059-1063, 2001.

UNIVERSIDADE FEDERAL DE VIÇOSA - UFV. Central de processamento de dados (UFV/CPD). Manual de utilização do programa SAEG (Sistema para análises estatísticas e genéticas). Viçosa, MG: Universidade Federal de Viçosa, 1997. 59p.

Van SOEST, P.J.; ROBERTSON, J.B. Analysis of forages and fibrous foods. Ithaca: Cornell University, 1985. 202p.

WEISS, W. Energy prediction equations for ruminant feeds. In: CORNELL NUTRITION CONFERENCE FOR FEED MANUFACTURERS, 61., 1999, Ithaca. Proceedings... Ithaca: Cornell University, 1999. p.176-185

ZEOULA, L.M.; KASSIES, M.P.; FREGADOLLI, F.L. et al. Uso de marcadores na determinação da digestibilidade parcial e total em bovinos. Acta Scientiarum, v.22, n.3, p.771-777, 2000. 